\title{
Uma pintura barroca: nuances do século XVII e da obra do Padre Antônio Vieira, um embaixador do evangelho nas cortes e nas matas
}

Pedro Silva Goudard Cruz ${ }^{1}$

http://lattes.cnpq.br/9243584022199332

Thiago Soares de Oliveira ${ }^{2}$

http://orcid.org/0000-0002-3078-0058

http://lattes.cnpq.br/9517999630235808

Felipe Vigneron Azevedo ${ }^{3}$

http://lattes.cnpq.br/1989403713464209

Enviado em: 31/08/2018

Aceito em: 07/01/2019

Resumo: Este artigo objetiva contextualizar a obra do Padre Antônio Vieira no panorama barroco do século XVII, percebendo como se exibem os valores que guiavam e as ideias que povoavam as mentes da época, além de deslindar as vertentes predominantes no discurso religioso do jesuíta. Parte-se, pois, de um esforço reflexivo a fim de estabelecer um verdadeiro diálogo entre áreas indissociáveis: a literatura e o contexto histórico. Por meio da pesquisa bibliográfica, dada a própria fonte de dados a que se recorre para o desenvolvimento da proposta, pretende-se promover um reflexão que sirva aos propósitos da Lei de Diretrizes e Bases da Educação Brasileira e dos Parâmetros Curriculares Nacionais para o Ensino Médio, ao propor um estudo que vá além da trivial memorização de datas e marcos.

Palavras-Chave: Literatura luso-brasileira. Barroco. Padre Antônio Vieira. Discurso religioso.

Abstract: This article aims to contextualize the work of Father Antônio Vieira in the baroque panorama of the XVII century, perceiving how the values that guided and the ideas that populated the minds of the time were exhibited, as well as to delineate the predominant aspects in the religious discourse of the Jesuit. It begins with a reflexive effort to establish a true dialogue between inseparable areas: literature and the historical context. Through bibliographic research, given the data source that is used for the development of the proposal, it is intended to promote a reflection that serves the purposes of the Brazilian Education Guidelines and Bases Law and the National Curricular Parameters for Secondary Education, by proposing a study that goes beyond the trivial memorization of dates and milestones.

Keywords: Luso-Brazilian literature. Baroque. Father Antônio Vieira. Religious speech.

\footnotetext{
${ }^{1}$ Licenciado em Letras (Português/Literaturas de Língua Portuguesa) pelo Instituto Federal Fluminense. Professor da Rede Privada de Ensino e Servidor Público da Prefeitura Municipal de São Fidélis. E-mail: pedrosgcruz@gmail.com

2 Doutor em Cognição e Linguagem pela Universidade Estadual do Norte Fluminense Darcy Ribeiro (UENF). Professor da Licenciatura em Letras e da Especialização em Literatura, Memória Cultural e Sociedade do Instituto Federal Fluminense. E-mail: so.thiago@hotmail.com

${ }^{3}$ Mestre em Teoria Literária e Literatura Comparada pela Universidade do Estado do Rio de Janeiro. Professor da Licenciatura em Letras e da Especialização em Literatura, Memória Cultural e Sociedade do Instituto Federal Fluminense. E-mail: felipevigneron@gmail.com
} 


\section{Considerações iniciais}

Sendo uma figura proeminente na seara do discurso religioso no período barroco luso-brasileiro, o Padre Antônio Vieira, pela sua habilidade argumentativa e pelos mecanismos de convencimento que emergem de seus sermões, tem sido um autor sobre cujas obras vários estudiosos se debruçam, apresentando-se Pécora (2014), Bosi (2015), Merquior (1996) e Moisés (2004) como principais referências para as análises.

Como a obra literária se circunscreve num período histórico, mantendo com ele um inegável vínculo, este trabalho objetiva contextualizar a obra de Vieira no estilo de época barroco luso-brasileiro, a fim de compreender os principais temas que surgem no sermonário do jesuíta, além de refletir sobre como os objetos de suas pregações se relacionam a ponto de fazer surgir, de uma aparente contradição, uma unidade exemplarmente afinada. Dessa forma, optou-se pela escrita de duas seções, sendo que a primeira delas é dedicada à apresentação de dados e de referências para melhor entender o século XVII na corte portuguesa e na colônia brasileira, ou seja, a conjuntura na qual viveu e trabalhou o jesuíta; a segunda, por sua vez, ressalta as ideias que permeavam a obra do sacerdote, como sua apaixonada visão sebastianista ${ }^{4}$, de modo que se possa vislumbrar o barroco jogo de contraste, oposição e congruência. Adota-se a metodologia bibliográfica, já que a principal característica dessa modalidade de pesquisa é o debruçar-se sobre publicações que contenham dados sobre o tema ou acerca do objeto pesquisado (TOZONI-REIS, 2010).

Para tanto, o propósito apoia-se na base teórica construída a partir de estudiosos que abordam o período barroco e a obra do autor, como Bosi (2015), Moisés (2004), Proença Filho (2012), Saraiva e Lopes (1996), entre outros, com o intuito de se "ter em mãos" os fins para os quais Vieira pregava na Europa e na América. Aliás, o estudo aqui proposto é socialmente relevante no sentido de poder ser aplicado em sala de aula, podendo colaborar para que se levantem questões importantes acerca do estilo de época barroco, para que se contextualize tal período para além de simples datas e fatos históricos e para que se entendam os valores que guiavam e as ideias que povoavam as mentes do século XVII. Note-se que a construção de uma visão crítica do mundo é recomendada pela Lei 9.394/96 (Lei de Diretrizes e Bases da Educação Nacional) e ressaltada pelos Parâmetros Curriculares Nacionais em sua segunda parte, relativa a Linguagens, Códigos e suas Tecnologias.

Por fim, este artigo não pretende esgotar as vias a partir das quais se pode entender o contexto do Barroco, mas situar a figura de Vieira como relevante autor desse período e, partindo disso, fornecer subsídios que possam ser aplicados em sala de aula na reflexão a respeito do pensamento que pairava nas mentes do século XVII.

\section{Uma Pintura Barroca}

Para apreciar o quadro do século XVII, é preciso considerar uma extensa gama de nuances, observando os diversos personagens que saltam aos olhos, dentre eles Vieira, e suas atitudes na grande cena. Entende-se, aqui, que o esforço de análise do passado não é de forma alguma desnecessário ou impertinente, pois, como ensina Massaud Moisés (2008),

\footnotetext{
${ }^{4}$ Crença religiosa, de teor messiânico, segundo a qual o rei D. Sebastião (1554-1578), desaparecido na batalha de Alcácer-Quibir, retornaria para libertar Portugal da coroa hispânica e reconduzir a nação a glórias maiores que as do passado.
} 
A realidade dos fatos mostra que, notadamente quando se trata do passado remoto, nenhum texto se deixa sondar em profundidade sem o auxílio da historiografia. É que a rigor, toda análise textual é contextual. E é-o não porque o afirmamos a priori, mas porque assim o ensina, reiteradamente, a experiência (MOISÉS, 2008, p. 21).

Dessa maneira, uma via segura para observar o fenômeno literário e social dos sermões do Padre Antônio Vieira é por meio do entendimento de seu contexto, ultrapassando a mera fixação de datas e fatos, mas compreendendo a sociedade seiscentista globalmente, como a grande pintura proposta, visto que os textos pertencem a esse "passado remoto", a esses primórdios da literatura brasileira. Assim, o estudo da prédica do jesuíta luso-brasileiro aqui proposto não quer se dar fora da contemplação desse intrincado e complexo cenário chamado século XVII, sob o risco de não conseguir o discernimento almejado para a questão suscitada.

Ao contemplar as artes visuais pertencentes ao estilo de época barroco, percebe-se um "culto do contraste", como chama Domício Proença Filho (2012, p. 143), "através de recurso ao exagero nos relevos, ao choque de colorido". De forma análoga, José Guilherme Merquior (1996, p. 23) define a arte barroca como "um estilo fundado em elementos beterogêneos e contrários, porém submetidos a uma síntese dinâmica". O painel que se tem do século XVII é igualmente este: época de contrários e antagonismos em permanente movimentação.

Merquior (1996) enumera os elementos que causam esses choques na incipiente Idade Moderna ${ }^{5}$, apontando mudanças nos campos político, econômico e ideológico que formarão essa composição de inversos com a tradição religiosa profundamente teocrática. Observa-se, nesse grande quadro do século XVII, o surgimento dos Estados nacionais, a instalação do aparelho mercantilista, o florescer da ciência moderna, assim como a resistência de elementos da tradição medieval religiosa.

Essa reação é a resposta, como afirma Bosi (2015), de um mundo católico diante do liberalismo protestante e do racionalismo ascendente em nações como Inglaterra, Holanda e França. É uma forma de assegurar a visão de mundo na qual os Estados surgidos, especificamente o português e o espanhol, recebem de Deus missões especiais e são destinadas ao triunfo.

Importante contemplar, então, esta tão marcante oposição: de um lado, católicos romanos; de outro, os diversos grupos contestadores cristãos, os protestantes. O processo desencadeado pelo martelar de Lutero na porta da Igreja do Castelo de Wittenberg teve como resposta o Concílio de Trento, realizado de 1545 a 1563, e o movimento gerado para rechaçar as novas ideias, a Contrarreforma. A essa reação devem-se os contornos mais importantes do quadro contemplado, seja em questões religiosas e políticas seja em questões artísticas, segundo Proença Filho (2012), num misto de confronto e conciliação entre valores opostos.

A propaganda católica resultante desse esforço contrarreformador descamba, na metrópole portuguesa, numa profusão da prosa doutrinal religiosa, incluindo sermões, biografias de santos e tratados moralistas, como afirmam Saraiva e Lopes (1996), em sua maioria objetivando o convencimento do público letrado, ou de armar de maneira suficiente aqueles que, por meio oral, iam a importantes campos de batalha da época: os púlpitos. O Sermão pelo Bom Sucesso das Armas de Portugal contra as de Holanda, pregado por Vieira em 1640, serve

\footnotetext{
${ }^{5}$ Estágio da história ocidental que tem início em 1453, com a tomada de Constantinopla pelos turcos otomanos e se estende até 1789, com a Revolução Francesa.
} 
de paradigma, tal como alega Moisés (2004), para a situação: de um lado, os católicos; de outro, os reformadores; de um lado, os fiéis no caminho certeiro rumo ao céu; de outro, aqueles que rolam pela ladeira rumo ao inferno; de um lado, enfim, os portugueses abençoados e instrumentos de Deus no mundo; de outro, as nações infiéis e pagãs.

Para entender toda a dinâmica desse século, também é preciso considerar um conjunto de "pintores" essenciais. A Companhia de Jesus, ordem religiosa fundada pelo espanhol Inácio de Loyola no ano de 1534 e à qual pertenceu o sacerdote Antônio Vieira, encarnou um papel fundamental durante a Contrarreforma. Inclinados para a atitude missionária, os jesuítas tinham como que escrito em seus corações os versos camonianos e eram por eles inspirados para dilatar a Fé e o Império, seja em confronto com o infiel, conforme explicado acima, seja em catequese aos "gentios" do Novo Mundo, tendo em vista "uma concepção triunfalista e messiânica da Coroa e da nobreza (rural e mercantil)", fomentada nas conjunturas portuguesas e espanholas pela aventura dos descobrimentos, segundo Bosi (2015, p. 29).

Possuidores do monopólio educacional na colônia ultramarina até 1759, os padres jesuítas foram responsáveis pela educação dos pupilos no Brasil, apresentando a eles a Ratio Studiorum ${ }^{6}$, método pedagógico formulado no fim do século XVI. Também o pequeno Vieira frequentou uma escola inaciana, tendo contato com o “caráter 'literário' e retórico do ensino jesuítico" (MOISÉS, 2004, p. 78), e ingressou na ordem religiosa, aspectos que contribuem para o entendimento de sua retórica e ação política.

Fator-chave para compreender o contexto no qual vive e trabalha o sacerdote católico é também o período denominado Domínio Filipino, que se inicia em 1580, após o desaparecimento do rei D. Sebastião na batalha de Alcácer-Quibir, e termina em 1640, com a Restauração ${ }^{7}$, durando sessenta anos. A tragédia do reino de Portugal ocorre em 1578, quando o Senhor da Guiné e da Conquista, Navegação e Comércio da Etiópia, Arábia, Pérsia e Índia, como era proclamado D. Sebastião, já “em plena bancarrota, tenta de novo a aventura cavalheiresca em Marrocos" (SARAIVA e LOPES, 1996, p. 437) e malogra absolutamente. Como o rei morre precocemente aos 24 anos e não deixa herdeiros, a coroa portuguesa passa às mãos de Felipe II da Espanha, neto do rei português D. Manuel I.

Sentindo a independência perdida e influenciado por trovas proféticas de um sapateiro chamado Gonçalo Annes Bandarra ${ }^{8}$, o povo português não aceita docilmente o jugo espanhol e colore o panorama da época com as cores fortes de um messianismo sebastianista, conforme declara Jean Delumeau (1989, p. 210): "No tempo da ocupação espanhola (15801640), recusa-se a acreditar na morte do rei Sebastião [...]. Ele retornará para restituir glória e liberdade a seu povo". Tal estudioso francês ressalta que o discurso sebastianista será utilizado nos sermões do Padre Antônio Vieira para os diferentes monarcas que se sucedem, revelando assim a tonalidade da qual se vestirá a prédica do sacerdote católico para a proclamação de Portugal como instrumento de Deus na terra e futuro império glorioso.

O período explica ainda a influência hispânica que sofrerá o Barroco brasileiro e elucida as sucessivas invasões holandesas ocorridas na colônia brasileira, reflexos do contexto

\footnotetext{
${ }^{6}$ Abreviação para Ratio atque Institutio Studiorum Societatis Iesu. Foi o conjunto de normas, planos, códigos e regimes que a Companhia de Jesus utilizou em todas as escolas a ela pertencentes até o ano de 1773.

${ }^{7}$ Movimento que aclamou D. João, duque de Bragança, como o novo rei de Portugal, com o nome de D. João IV, em dezembro de 1640, dando fim ao domínio filipino (não sem o conflito armado) e início à dinastia de Bragança, que governaria até o início do século XX.

8 Sapateiro e poeta nascido por volta de 1500, em Trancoso, Portugal, e falecido em meados do século XVI. De grande erudição e conhecimento bíblico, escreve textos apontando para o retorno glorioso de D. Sebastião.
} 
mercantilista pelo qual o mundo ocidental passava e que dará condições necessárias à Restauração portuguesa, tal como asseveram Saraiva e Lopes (1996), por meio do desenvolvimento de uma burguesia comercial lusitana e da obstinação popular ao domínio espanhol, traduzida na profusão literária de intensa resistência antifilipina.

As terras americanas ocupadas pelos portugueses inserem-se nesse contexto como "sistema agromercantil, voltado para a máquina econômica europeia" (BOSI, 1992, p. 26), fonte de riquezas e grande engenho a gerar capital para a metrópole. Esse sistema demandou, consoante também assinalado por Bosi, as tonalidades do tráfico negreiro e da cultura da cana, completando-se no plano exterior com o "ciclo de fluxo e refluxo da mercancia colonizada na linha das flutuações do mercado e sob o império da concorrência entre os Estados metropolitanos" (BOSI, 1992, p. 26). Concorrência essa que explicará as invasões holandesas supracitadas, considerando-se a disputa entre a Espanha, englobando na época também o Império Português, e a Holanda.

A prédica do Padre Antônio Vieira revela que o jesuíta "sabia que a máquina mercante viera para ficar, irreversível, inexorável” (BOSI, 1992, p. 120), sendo necessário subjugá-la para os interesses de Deus - a propagação de sua Palavra - e do Reino - o alargamento de seus domínios. Seus sermões convocam todas as classes para a urgente missão de reconstruir o império lusitano, aventando hipóteses que causaram contestações ferrenhas na corte, como o pagamento de impostos por nobres e religiosos e a criação de uma Companhia das Índias Ocidentais recorrendo a capitais judaicos.

As tonalidades mais sombrias desse imenso e complexo painel ficam por conta do Brasil, num barroco jogo de contraste com o fulgor e brilho da opulência metropolitana. Já passadas muitas décadas do descobrimento de novas terras, a colonização se dava ainda sem adentrar na extensa área que daria origem ao contemporâneo território nacional. Ao longo do litoral, arquipélagos urbanos gradualmente surgiam, de maneira esparsa, com os olhos voltados para o Atlântico que os conectava a Portugal e, muitas vezes, sem contato entre si.

A "máquina mercante" que levava o açúcar e outros produtos das fazendas também moía qualquer possibilidade de desenvolvimento. Caio Prado Júnior (2011, p. 131) ressalta que a colônia era tida por grande propriedade extrativista, já que "o Brasil existia para fornecer-lhe [Portugal] ouro e diamantes, açúcar, tabaco e algodão. Assim entendia as coisas e assim praticava". Todos os atos administrativos da Coroa eram pensados para favorecer a estrutura rural da colônia e coibir aqueles que pudessem fugir da vocação agropecuária ou extrativista. Vocação afinada ao "espírito da dominação portuguesa [...] que cuidou menos em construir, planejar ou plantar alicerces, do que em feitorizar uma riqueza fácil e quase ao alcance da mão" (HOLANDA, 1995, p. 95).

Dessa forma, nas diversas ilhas da civilização embrionária dos trópicos, muitos dos arranjos se repetiam, tendo como elite "uma camada de latifundiários com seus interesses vinculados a grupos mercantis europeus dentre os quais se destacavam os traficantes de escravos africanos" (BOSI, 1992, p. 23). Tal elite se mantinha pela exploração da mão de obra escrava e exercia o poder político no seu círculo mais próximo, aproveitando o vazio de autoridade numa terra que começava a ser explorada.

A Companhia de Jesus, ordem à qual pertence o personagem mais observado neste quadro, exerce neste cenário a "prática de uma Igreja supranacional" (BOSI, 1992, p. 25), seguindo as intenções primeiras da colonização de cristianizar os povos desconhecidos. Com o passar dos tempos, no entanto, a elite latifundiária se oporá aos jesuítas, exercendo forte pressão para poder utilizar também a mão de obra indígena escravizada; neste 
momento, Vieira estará presente para marcar com fortes cores o quadro a que se esteve observando. De quem é a causa defendida pelo jesuíta?

\section{Embaixador do Evangelho}

Em sua carta à comunidade de Éfeso, o apóstolo Paulo de Tarso se proclama embaixador da boa-nova, da mensagem cristã dirigida a todos os povos, pedindo que a Igreja primitiva ore pelo seu trabalho missionário. Desde os primórdios do cristianismo (séc. I), portanto, o caráter evangelizador se fez presente na vida da Igreja Católica, traduzindo-se nos diferentes e renovados esforços de conversão e "arrebanhamento" de um número sempre o maior possível de fiéis.

Seguindo uma característica que remonta à Antiguidade grega, conforme apontado por Bosi (1992), a argumentação utilizada para a instauração do processo colonizador era a própria vontade divina. Substituiu-se o politeísmo pelo culto ao único deus hebraico-cristão, mas preservou-se a base justificatória: expandir o Império era, afinal, expandir a religião e a Palavra salvadora. Desse modo, a empreitada das grandes navegações leva aos quatro cantos do globo o "bom evangelho dos cassetetes", como versificado pelo poeta moçambicano José Craveirinha?.

$\mathrm{Na}$ América portuguesa, a situação, mesmo apresentando contornos próprios, expunha linhas gerais similares: uma população nativa rotulada como bárbara e pagã, dona de um território muito valioso para não ser explorado. "A maldição mais comum nesta matéria é deixarmo-nos iludir, de boa fé, por uma hipocrisia coletiva, hábil em enunciar mal os problemas para melhor legitimar as soluções que se lhe aplicam” (CÉSAIRE, 1978, p. 14). Nessa intrincada rede de interesses, complexo tabuleiro de conflitos ainda nas primeiras décadas de efetivo trabalho colonizador, destaca-se a influente figura do Padre Antônio Vieira. Desfilam tantas facetas do jesuíta diante de seus ouvintes e leitores que paira a dúvida de qual evangelho é embaixador o orador luso-brasileiro, visto que, "Vieira foi um espírito atraído por motivos ideológicos contraditórios" (MERQUIOR, 1996, p. 30); um espírito essencialmente barroco, portanto.

Uma das características que é atribuída ao sacerdote, a título de exemplo, por Merquior (1996), é o ardor pela propagação do evangelho cristão entre os pagãos dos novos territórios descobertos por Portugal e aqueles que, de modo geral, ainda não conhecem a mensagem divina. Esse ardor seria revelado na vigorosa defesa que Vieira fez da população indígena, como mostra o Sermão da Epifania. No texto, o jesuíta assinala a igualdade entre as nações e o despropósito da escravidão:

As Nações, umas são mais brancas, outras mais pretas, porque umas estão mais vizinhas, outras mais remotas do Sol. E pode haver maior inconsideração do entendimento, nem maior erro do juízo entre homens, que cuidar eu que hei de ser vosso Senhor, porque nasci mais longe do Sol, e que vós haveis de ser meu escravo, porque nascestes mais perto?! (VIEIRA, 2014a, p. 621).

Como pode haver, questiona a lógica do sacerdote, senhores e escravos entre irmãos, entre filhos e criaturas de um mesmo Deus? Como tal condição exploratória pode ser explicada pelo simples fato de algumas peles serem mais queimadas pelo sol, como se acreditava na época? Da mesma maneira, o jesuíta, posteriormente, sai em defesa dos negros,

${ }^{9}$ Verso do poema “Aparências”, extraído do livro Obra poética. 
seguindo raciocínios análogos, como se pode ler em outros de seus sermões ${ }^{10}$.

Mesmo assim, percebe-se "uma retórica menor, que trabalha ad hoc, particularista e interesseira" (BOSI, 1992, p. 134), que renuncia os fundamentos éticos e morais para tentar uma conciliação. Numa retorcida argumentação, a dignidade dos filhos de Deus é preterida pela urgente necessidade de mão de obra nas diversas frentes de trabalho. Num movimento tipicamente barroco, ideias antagônicas são colocadas lado a lado, numa sociedade que presenciava o embate e o baile entre a tradição e a mudança.

Se não mais o isento porta-voz da igualdade entre os povos, começa a surgir o vulto de um Antônio Vieira extremamente pragmático, o influente orador que marcará a vida política do império lusitano durante o século XVII. A condescendência que o sacerdote apresenta ao adocicar o fel da escravidão de indígenas e africanos é sinal, como assevera Bosi (1992, p. 120), de que o padre, muito consciente das mudanças que seu tempo impunha, percebe o poder da "máquina mercante" que dita o novo ritmo do mundo e o quão urgente é que Portugal domine os novos mecanismos para concorrer em posição justa com as outras nações.

Para chegar ao objetivo da consolidação de uma potência lusitana, Vieira propõe a criação de uma Companhia das Índias Ocidentais, nos moldes das companhias criadas pela Inglaterra e pela Holanda, que seria a responsável única pelo comércio dos principais alimentos consumidos na metrópole e funcionaria sob a defesa armada de Portugal. Sob o mando de D. João IV, tal empreendimento chega a ser lançado, tendo por origem um capital essencialmente judeu. A proveniência de boa parte dos recursos utilizados não agradou a maioria de seus ouvintes, ainda afastados da "plena hegemonia do pensamento burguês" (BOSI, 1992, p. 120). Não obstante, o pregador insiste na institucionalização da Companhia, tábua de salvação no enfrentamento da nova geopolítica, caracterizada pelas competições em nível global por matéria-prima e mercado consumidor.

A dificuldade encontrada é mais geral, inclusive. O desafio do Padre Antônio Vieira era fazer com que o estranhamento da corte portuguesa com o pensamento mercantil, burguês, fosse superado. Em nome desse objetivo, como era o do erguimento da potência portuguesa, o orador trabalha para justificar os meios, revelando intenso pragmatismo e bastante modernidade. Da mesma forma, é necessário atualizar o Estado português por meio da perda da noção segundo a qual a essência de seus cidadãos era definida pela classe social à qual pertenciam ${ }^{11}$. Era preciso fazer valer essa posição, exercendo cada um seu papel da melhor forma possível na estrutura lusitana: "Cada um é as suas ações, e não é mais nem menos [...]" (VIEIRA, 2011, p. 425).

Enganar-se-ia, no entanto, quem visse nesse clamor do jesuíta apenas o político visionário, o pragmático inventivo. O motor que impulsiona a obra de convencimento empreendida por Padre Antônio Vieira é a crença na glória futura do reino de Portugal; uma glória que, mesmo já profetizada nas trovas do sapateiro Bandarra, precisa ser construída imediatamente pelos portugueses, de modo a "completar um desenho providencial que, para além de todos os obstáculos presentes, deve ser firmemente realizado na história" (PELOSO, 2007, p. 11). Muito mais que um grande império, a convicção do jesuíta era de que haviam sido eleitos os portugueses para serem o instrumento da implantação do reino divino na terra.

\footnotetext{
${ }^{10}$ Conforme apontado por Bosi (1992, p. 143), “sermões XIV, XVI, XX e XXVII do Rosário".

${ }^{11}$ A sociedade portuguesa se organizava pelas ordens. Nobreza e clero ocupavam o topo da pirâmide social, e o povo sustentava a base, havendo uma burguesia pouco desenvolvida ainda.
} 
A fagulha que faltava para incendiar as esperanças messiânicas em Portugal foi a revolução anticastelhana de 1640 (DELUMEAU, 1989). Mesmo que o rei D. Sebastião não tenha ressuscitado, Vieira continua a exercer seu contumaz trabalho de interpretação das Escrituras e dos tempos para fazer ver nas frontes coroadas do império lusitano a testa que irá à frente de seu país e do resto do globo, numa parceria arraigada com o pontífice romano, a um tempo de paz, glória e felicidade.

Há de haver um novo estado diferente do que até agora tem havido, em que todas as nações do Mundo hão de crer em Cristo Senhor nosso, e abraçar nossa Santa Fé Católica; e que há de ser tão copiosa a graça de Deus, que todos, ou quase todos os que então viverem, se hão de salvar, para se perfazer o número de predestinados (MUHANA, 1995, apud PELOSO, 2007, p. 49).

Assim explicou-se Vieira, utilizando-se dos textos sagrados e da interpretação de papas e santos doutores, diante do tribunal do Santo Ofício, que foi acionado para intervir na publicidade dessas ideias e, dessa forma, combater os inúmeros equívocos que poderiam afastar os fiéis do caminho da verdade, segundo a ótica de Roma. Afinal, apontar um tempo de justiça sobre a terra, e que devia ser instaurado pelos próprios cidadãos deste futuro império cujo poder é terreno e divino simultaneamente, confronta a ação pedagógica de mostrar um julgamento celeste iminente, capaz de comover corações e transformar comportamentos. Postergar o Juízo Final para depois dos mil anos do aprisionamento de Satã era de tranquilidade para os cristãos, significava proclamar um reino de justiça e igualdade, como explicado anteriormente, segundo a interpretação dos milenaristas para o capítulo 20 do Livro do Apocalipse de São João (DELUMEAU, 1989), e fazer suspirar por essas mesmas justiça e igualdade, o que poderia ser perigoso para a manutenção do status quo.

Ao analisar a obra do Padre Antônio Vieira por meio da observação desses traços mais marcantes, pode parecer existir uma profunda contradição entre as diferentes faces dos sermões, reflexos de interesses e inspirações diversas. As aparentes incoerências para a contemporaneidade são esclarecidas porque

Seria inócuo considerar a qualidade de seus textos fora de sua propriedade retórico-política, como, ainda mais, não seria possível caracterizar corretamente uma e outra isentando-as de seu peso teológico e, com ele, de seu vetor teleológico (PÉCORA, 1994, p. 41).

O sacerdote, revestido da autoridade divina e eclesial, é capaz de interpretar as sagradas escrituras para o povo e os fatos históricos à luz dessas escrituras, apontando suas causas e consequências; para isso, lança mão da prática e destreza retóricas, a fim de convencer seus ouvintes a embarcarem no imprescindível projeto da formação e consolidação do corpo místico de Cristo, a comunidade de fiéis organizada num Estado católico.

As principais ideias encontradas nos sermões do padre luso-brasileiro, aqui expostas sucintamente, estão ordenadas, portanto, segundo essa "unidade semântica" (PÉCORA, 2014, p. 25). Convocam-se todos os povos à fraternidade, porém sob o signo da cruz. Clama-se pela liberdade dos índios e negros, mas não para que eles vivam a seu modo, e sim para que tenham condições de serem cidadãos do Reino de Deus na terra. Apoia-se o aparelho mercantil para dar as bases econômicas a esse império que virá. Elege-se Lisboa como capital dessa nova sociedade e, assim, suspira-se pelo, brilhante aos olhos do pregador, futuro de Portugal.

Vieira é o embaixador por excelência dessa nova ordem que deve se instaurar, 
afastando-se dos princípios de Maquiavel de razão autônoma de Estado ${ }^{12}$, baseando-se na "lei natural implantada por Deus na Criação" (PÉCORA, 2014, p. 21). Pode-se contemplar, dessa maneira, que o espírito atraído por antagonismos, conforme trecho anteriormente citado de Merquior (1996), na verdade é capaz de costurar na tessitura de seus sermões os contrários para visualizar e fazer com que também seus ouvintes visualizem a segunda encarnação de Cristo, seu corpo místico atuante na sociedade.

\section{Considerações finais}

Neste artigo, apoiando-se nos autores que estudaram profundamente o período analisado, foi desenhado o rico panorama do século XVII, cenário no qual o Padre Antônio Vieira viveu e cultivou sua obra oratória. A pintura consequente, seguindo o próprio estilo dos seiscentos, o Barroco, apresentou os importantes contrastes e dissentimentos, movimentos de embate e conciliação, num processo que teve profunda influência na literatura da época, sendo chave de fundamental importância para a compreensão dos sermões do jesuíta. No painel são verificadas as dinâmicas envolvendo a Reforma e a Contrarreforma, a União Ibérica e a Restauração de Portugal, a crença no retorno de D. Sebastião e a sucessão de soberanos no trono lusitano, os soldados da Companhia de Jesus e suas frentes de batalha, a colônia situada no outro lado do Atlântico, sua relação com a metrópole portuguesa e sua posição na geopolítica da época.

Diante de um quadro com opostos tão marcados e, ao mesmo tempo, nuances discretas, fez-se necessário deslindar os traços principais da obra de Vieira, buscar de quais convicções o jesuíta era embaixador ao estar no púlpito. A imprescindibilidade surgiu também da aparente contradição manifesta. Como linhas gerais do sermonário do sacerdote católico, foram identificadas a busca pelo direito dos índios de receberem os ensinamentos e preceitos dos missionários religiosos, o alerta para que a economia de Portugal se modernizasse, a fim de competir com as outras potências globais, a convicção num futuro glorioso para o Império lusitano e, como que enlaçando todas as outras vertentes de sua obra, o vislumbre da composição de um corpo místico, tendo por cabeça o próprio Cristo e por assessores diretos as majestades de Lisboa e Roma. O indício dessa comunidade coesa justifica a ânsia pelo "arrebanhamento" cada vez maior de almas e, de modo concomitante, o esforço pelo desenvolvimento econômico português, caminho para a concretização dos planos divinos.

\section{Referências}

BOSI, A. Dialética da colonização. São Paulo: Companhia das Letras, 1992.

História concisa da literatura brasileira. São Paulo: Cultrix, 2015.

BRASIL. LDB. Lei 9394/96 - Lei de Diretrizes e Bases da Educação Nacional. Disponível em: < www.planalto.gov.br >. Acesso em: 25 jun. 2017.

Parâmetros curriculares nacionais (Ensino Médio) - Linguagens, Códigos e suas Tecnologias. Brasília: 2006. Disponível em: <http://portal.mec.gov.br/seb/arquivos/\%20pdf/book_volume_01_internet.pdf>. Acesso em: 25 jun. 2017.

\footnotetext{
12 "E deve-se compreender o seguinte: que um príncipe, especialmente um príncipe novo, não pode praticar todas aquelas coisas pelas quais os homens são considerados bons, sendo muitas vezes obrigado, para manter o estado, a agir contra a fé, a amizade, a humanidade e a religião" (MAQUIAVEL, 2011, p. 141).
} 
CÉSAIRE, A. Discurso sobre o colonialismo. Trad. Noémia de Sousa. Lisboa: Livraria Sá da Costa Editora, 1978. Disponível em: < https://antropologiadeoutraforma.files.wordpress.com/2013/04/aime-cesaire-discurso-sobre-o-colonialismo.pdf $>$. Acesso em: 21 jan. 2018.

CRAVEIRINHA, J. Obra Poética. Maputo: Direcção de Cultura, Universidade Eduardo Mondlane, 2002. Disponível em: <http://www.antoniomiranda.com.br/poesia_africana/mocambique/jose_craveirinha.html $>$. Acesso em: $20 \mathrm{fev}$. 2018.

DELUMEAU, J. História do medo no ocidente: 1300-1800, uma cidade sitiada. Trad. Maria Lucia Machado. Trad. das notas Heloisa Jahn. São Paulo: Companhia das Letras, 1989.

HOLANDA, S. B. de. Raízes do Brasil. São Paulo: Companhia das Letras, 1995.

MAQUIAVEL, N. O Príncipe. Trad. Dominique Makins a partir da edição inglesa de W. K. Marriot. São Paulo: Hunter Books, 2011.

MERQUIOR, J. G. De Anchieta a Euclides: breve história da literatura brasileira I. Rio de Janeiro: Topbooks, 1996.

MOISÉS, M. A Análise Literária. São Paulo: Cultrix, 2008.

. História da literatura brasileira: Vol. I - Das Origens ao Romantismo. São

Paulo: Cultrix, 2004.

PÉCORA, A. Teatro do sacramento: a unidade teológico-retórico-política dos sermões de Antônio Vieira. São Paulo: Editora da Universidade de São Paulo; Campinas: Editora da Universidade de Campinas, 1994. Disponível em: <https://books.google.com.br/books/about/Teatro_do_sacramento.html?id=lMLYTfZmDlgC\&redir_esc=y $>$. Acesso em: 18 dez. 2017.

PELOSO, S. Antônio Vieira e o Império Universal: a Clavis Prophetarum e os documentos inquisitoriais. Trad. Sonia Netto Salomão e Simone Celani. Rio de Janeiro: De Letras, 2007.

PRADO JÚNIOR, C. Formação do Brasil Contemporâneo. São Paulo: Companhia das Letras, 2011.

PROENÇA FILHO, D. Estilos de época na literatura. São Paulo: Prumo, 2012.

SARAIVA, A. J.; LOPES, Ó. História da literatura portuguesa. Porto: Porto Editora, 1996.

TOZONI-REIS, M. F. de C. Metodologia da pesquisa. Curitiba: IESDE, 2010.

VIEIRA, A. Essencial Padre Antônio Vieira / organização e introdução Alfredo Bosi. São Paulo: Penguin Classics Companhia das Letras, 2011.

$2014 \mathrm{a}$.

Sermões - Tomo I / organização e introdução Alcir Pécora. São Paulo: Hedra,

Sermões - Tomo 2 / organização e introdução Alcir Pécora. São Paulo: Hedra, 2014b. 